\section{AB0516 SACROILIAC JOINTS MRI PERFORMED BY A BLINDED AND UNBLINDED RHEUMATOLOGISTS AND A RADIOLOGISTS AFTER AND WITHOUT SPECIAL MRI TRAINING}

E. Vasilenko ${ }^{1,2}$, I. Gaydukova ${ }^{1}$, V. Mazurov ${ }^{1}$, R. Samigullina ${ }^{1}$, A. Dadalova ${ }^{1}$, I. Crylov ${ }^{3}$, A. Krylova ${ }^{3} .{ }^{1}$ North-Western State Medical University named after I. I. Mechnikov, St. Petersburg, Russia, Department of Therapy, Rheumatology, Examination of Temporary Disability and Quality of Medical Care named after E.E. Eichwald, St. Petersburg, Russian Federation; ${ }^{2}$ Clinical Rheumatology Hospital №25, outpatient department, St. Petersburg, Russian Federation; ${ }^{3}$ Clinical Rheumatology Hospital №25, radiology department, St. Petersburg, Russian Federation

Background: Despite of the development the criteria for the diagnosis of axial spondyloarthritis (axSpA) the problem of late axSpA diagnostics is not resolved. The difficulties in the assessment of MRI sacroilitis (SI) could be of the reasons of axSpA diagnostic delay.

Objectives: to evaluate the inconsistency in the assessment of sacroiliac joints MRI that was performed by a blinded and unblinded rheumatologists and a radiologists.

Methods: The assessment of 80 magnetic-resonance tomograms of sacroiliac joints (SIJ) was performed by 4 independent readers, one which was blinded to clinical data radiologist (BR), another radiologist was informed that the study was performed for axSpA (unblinded radiologist - UR), another 2 readers were blinded to diagnosis rheumatologists. One of the rheumatologists was trained in SIJ MRI (BTRh), another rheumatologist was not trained specially in MRI of SIJ (BURh). The study was carried out on the magnetic resonance tomography (GE Discovery MR750W 3.0T) in T1 and STIR regimens. $65 \mathrm{MRI}$ were performed in pts that fulfilled the ASAS criteria for the axSpA and history of active SII (bone marrow edema) on previous SIJ MRI. According CT of SIJ 25 (38.5\%) of these pts had nr-axSpA, $22(33.8 \%)$ had SI grade II / III, in $18(27.7 \%)$ of the pts SI grade IV was detected. $15 \mathrm{MRI}$ scans were performed in healthy volunteers who did not meet the ASAS 2009 criteria at the time of the study and had no CT changes in SlJ.

The number of detected by each reader cases of active SII as defined by ASAS were analyzed with the calculation of the inter-reader reliability.

Results: There was found that there was inter-reader reliability between results of blinded and unblinded radiologists $(73.8 \%)$ with statistical differences in the number of detected and undetected signs of SII $(p<0.05)$.

The inter-reader reliability scores between the unblinded rheumatologist and the radiologist were $97.5 \%$ and did not have statistically significant statistical differences $(p \geq 0.05)$

And for a trained rheumatologist and a blinded untrained rheumatologist it was $53.5 \%$ and had significant statistical differences $(p<0.05)$

The results of 4 readers SIJ MRI assessments are presented at Table 1

Table 1. The results of MRI sacroiliitis assessments performed by blinded and unblinded radiologists and rheumatologists

\begin{tabular}{lcccc}
\hline & BR & UbR & BtRh & BURh \\
\hline Revealed SII in axSpA $(\mathrm{n}=65), \mathrm{n}(\%)$ & $44(67.7)^{\star}$ & $64(98.5)^{\#}$ & $62(95.4)$ & $26(40)^{\star}$ \\
Undetected SII in axSpA $(\mathrm{n}=65), \mathrm{n}(15)$ & $21(32.3)^{\star}$ & $1(1,5)$ & $3(4.6)$ & $39(60)^{\star}$ \\
Revealed SII in controls $(\mathrm{n}=15), \mathrm{n}(\%)$ & $2(13.3)^{\star}$ & $3(20)^{\#}$ & $3(20)$ & $1(6.7)^{\star}$ \\
Undetected SII in controls $(\mathrm{n}=15), \mathrm{n}(\%)$ & $13(86.7)^{\star}$ & $12(80)^{\#}$ & $12(80)$ & $14(93.3)^{\star}$
\end{tabular}

*inter-reader reliability with the results of all another reader with $p<0.05$. \# inter-reader reliability between unblinded radiologist (UR) and blinded treated rheumatologist (BtRh) with $p<0.05$. BURh - blinded untreated rheumatologist. BR - blinded radiologist.

Conclusion: The better agreement in inter-reader reliability in MRI of SIJ assessment was detected between unblinded radiologist and trained blinded rheumatologist. Blinded radiologist had shown lower inter-reader agreement with another specialists. The lowest of all inter-reader agreement had shown untrained blinded rheumatologist. Special MRI of SII assessment trainings for rheumatologists and radiologists are unmet need for the improvement of in-time axSpA diagnostics.

Disclosure of Interests: None declared.

DOI: 10.1136/annrheumdis-2021-eular.3861

\begin{tabular}{l|l}
\hline AB0517 & THE HIDDEN FACE OF SMOKING IN AXIAL \\
SPONDYLOARTHRITIS
\end{tabular}

S. Bouden ${ }^{1}$, L. Kharrat ${ }^{1}$, A. Ben Tekaya ${ }^{1}$, O. Saidane ${ }^{1}$, R. Tekaya ${ }^{1}$, I. Mahmoud ${ }^{1}$, L. Abdelmoula'. ${ }^{1}$ Hospital Charles Nicolle, Rheumatology, Tunis, Tunisia

Background: The deleterious effect of smoking on spondyloarthritis has been studied for several decades. Indeed, smoking increases inflammation and disease activity, hence, promotes bone damage.
Objectives: The aim of our study was to evaluate the clinical, biological and radiological impact of smoking on axial spondyloarthritis (axSpA).

Methods: We conducted a retrospective study including patients meeting the Assessment of SpondyloArthritis international Society (ASAS) criteria between 2000 and 2020

The following parameters were collected: age, smoking, ASDAS, BASDAI, and BASFI. We also measured inflammatory biomarkers (erythrocyte sedimentation rate (ESR) and C-reactive protein (CRP)).

Results: We included 138 patients. Sixty-eight per cent of them were males The mean age was $45.73 \pm 12.66$ years. The mean age at the disease onset was $28.89 \pm 12.54$ years. The mean CRP was $33.38 \pm 39.65 \mathrm{mg} / \mathrm{dL}$. The mean BASDAI and ASDAS-CRP were $4.21 \pm 2.23$ and $3.06 \pm 1.26$, respectively. The mean BASFI was $4.77 \pm 2.58$

Fifty-one of our patients were smokers (37\%). They were 48 men and 3 women. The mean pack-year was $45 \pm 17.15$.

Smokers had a significantly younger age of the disease onset $(25.21 \pm 11.37$ versus $31.96 \pm 12.67, \mathrm{p}=0.009$ )

Moreover, patients who smoke Tabaco had developed significantly more ankylosis compared to patients who don't $(p=0.026)$.

Osteoporosis was also more frequent in smoking patients $(p=0.032)$.

However, no association was found between smoking and ESR, CRP, ASDASCRP, BASDAI and BASFI.

Conclusion: Our results reveal that smoking can be responsible of a younger axSpA onset, and can lead to more severe structural damages regardless the disease activity. This highlights the importance of smoking cessation in preventing early bone damage in axSpA.

Disclosure of Interests: None declared.

DOI: 10.1136/annrheumdis-2021-eular.3924

\section{AB0518 ATHEROSCLEROTIC RISK IN PATIENTS WITH ANKYLOSING SPONDYLITIS: BIOMARKERS VERSUS SCORE}

R. Dhahri ${ }^{1}$, S. Miri ${ }^{1}$, M. Slouma ${ }^{1}$, B. Louzir ${ }^{1}$, L. Metoui ${ }^{1}$, I. Gharsallah ${ }^{1}{ }^{1}$ The Military Hospital of Tunis, Rhumatology, Tunis, Tunisia

Background: Chronic inflammatory rheumatic diseases are associated with a high cardiovascular risk. However, data in ankylosing spondylitis (AS) are still limited.

Objectives: The aim of our study was to assess the atherosclerotic risk in patients with AS, by comparing the Systematic coronary risk evaluation: SCORE, with biomarkers of atherosclerosis: High sensitivity C-reactive protein (Hs-CRP), LDL/HDL ratio and apoliprotein A1 (Apo A) /apolipoprotein B (Apo B) ratio.

Methods: We conducted a cross-sectional observational study of 40 patients with AS, over a period of 3 months. Socio-demographic data, clinical character istics of the disease, as well as biological, radiological and therapeutic data were collected for each patient. Coagulated blood samples were collected following a 12-hour fast. Cardiovascular risk was considered high for $\mathrm{Hs}-\mathrm{CRP}>3.0 \mathrm{mg} / \mathrm{L}$ [1], LDL/HDL> 3.5 in men and 3.0 in women [2], and ApoB/ApoA level>0.9 [3,4] SCORE was calculated for all patients.

Results: The mean age of our population was $44 \pm 10$ years. Male predominance was noted with a sex ratio $=11$.1. The mean ASDAS-CRP and BASDAI levels were $2.1 \pm 0.95$ and $2.25 \pm 1.33$. Thirty-two percent of the patients had a high risk of cardiovascular diseases according to Hs-CRP level, with an average of $10.7 \mathrm{mg} / \mathrm{L}$. The mean LDL/HDL ratio was high in twenty-two percent of the patients. The mean value of $A p o A 1$ and $A p o B$ was respectively $1.3 \mathrm{~g} / \mathrm{l}$. and $0.9 \mathrm{~g} / \mathrm{l}$. Low values of $A p o A 1$ were determined in $12.5 \%$ of the subjects, and high values of $A p o B$ were found in $15 \%$ of subjects. The mean value of $A p o A / A p o B$ ratio was 0.7 . Ten percent of the studied subjects had an unfavourable $A p o B / A p o A 1$. The predicted 10 -year risk of CV mortality according to SCORE was high in $5 \%$ of the patients very high in $2.5 \%$ and moderate in $35 \%$ of them. Over 17 patients with moderate, high and very high risk according to SCORE: Four patients $(23.5 \%)$ had high LDL/HDL ratio, 8 (47\%) had high waist/hip ratio, 5 (29.4\%) had high Hs-CRP level, and 2 (11.7\%) had high ApoB/ApoA ratio.

We found $A p o B / A p o A$ to be positively correlated with Hs-CRP ( $r=0.31, p=0.05$ ). The SCORE was correlated to the age at the onset of the disease $(r=0.78$, $\mathrm{p}<10^{-3}$ ).

Conclusion: The atherosclerotic risk in our population ranged from 10 to $43 \%$. SCORE presented with the highest percentage, making it more suitable for mass screening. Biomarkers on the other hand are more precise. Hs-CRP is biomarker to be included in daily practice, even when AS is in remission. Accuracy of the apoB/apoA ratio is significantly great and appears to be associated with inflammation.

REFERENCES:

[1] Myers GL, Rifai N, Tracy RP, Roberts WL, Alexander RW, Biasucci LM, et al. CDC/AHA Workshop on Markers of Inflammation and Cardiovascular Dis ease: Application to Clinical and Public Health Practice: Report From the 